\title{
Common Pitfalls in the Management of Bone Metastasis of the Extremities - a Current Concept and Systematic Review of the Literature
}

\author{
DIETMAR DAMMERER, PHILIPP BLUM, DIETMAR KRAPPINGER and ALEXANDER KEILER
}

\author{
Department of Orthopaedics and Traumatology, Medical University of Innsbruck, Innsbruck, Austria
}

\begin{abstract}
Background/Aim: The surgical treatment of patients with bone metastasis of the extremities poses a set of unique challenges. We aimed to highlight common hazards when treating pathological fractures as well as hazards surrounding assumptions on metastatic status and life expectancy. Materials and Methods: This systematic literature review includes studies published from January 1, 1985 to May 7, 2021. Published articles were surveyed using PubMed. Of 99 studies, 32 original articles were found to meet the inclusion criteria. The PRISMA guidelines were used to select articles. Results: Current literature reports a variety of common pitfalls. In order to avoid pitfalls, it is essential to secure the diagnosis. Furthermore, life expectancy must be given consideration when planning surgical therapy. In addition, a well-functioning multidisciplinary team is needed to coordinate further options such as radiation or embolization. Conclusion: Despite the fact that the surgical principles for treating bone metastases of the extremities are often to the point, incorporating all the nuances of treatment is a meticulous procedure.
\end{abstract}

A pitfall is an imperceptible hazard that often produces unforeseen difficulties and an unwanted result (1). Treating patients with metastatic disease means circumnavigating numerous potential pitfalls, many of which stem from the physician's bias when treating patients with "palliative" intent (1). In some cases, metastatic cancer of the bone

This article is freely accessible online.

Correspondence to: Philipp Blum, MD, Department of Orthopaedics and Traumatology, Medical University of Innsbruck, Anichstrasse 35, 6020 Innsbruck, Austria. Tel: +43 51250422691, e-mail: philippblum1@gmx.de

Key Words: Pathological fracture, bone metastases, skeletal metastases, pitfalls, literature review. requires consideration similar to primary sarcomas of the bone, while in other cases the palliative aims are obvious (1). The literature reports that approximately four million people experience bone pain from a malignant disease (2), with metastatic bone pain being one of the major complaints (2, 3). Additionally, bone metastases are a leading cause of comorbidity, characterized by pain, pathological fractures (impending and complete), impaired mobility, and potential neurological compromise (4).

The spread of malignant cells from the primary tumor to other sites proceeds in a number of highly selective steps known as the metastatic cascade (5). Only $0.02 \%$ of malignant cells that enter the bloodstream are estimated to result in clinically detectable metastases (6). Histopathologically, the metastatic cascade commences when malignant cells are released by the primary tumor $(5,7)$. These cells subsequently invade healthy tissue and pass into the bloodstream by traversing the basal membrane of blood vessels or lymphatics $(5,7)$. The malignant cells leave the vessels and settle in a new organ away from the primary tumor, where they form metastases $(5,7)$.

When bone metastases are established, median survival is reported to range from two to three years in breast cancer, two years in prostate cancer, and not even one year in lung cancer (8). However, it can also be substantially shorter, for example six months in melanoma, six to seven months in lung cancer or six to nine months in bladder cancer $(5,9-13)$.

According to the literature, the lung, the liver and, in third place, the bone are the most frequent sites of metastasis (9). Prostate and breast cancer cause up to $70 \%$ of skeletal metastases $(3,10)$. Bone metastases can occur on their own or together with visceral metastases; patients with bone-only metastases are reported to have best survival $(11,12)$. Nevertheless, bone metastases can also present as the first evidence of metastatic disease (14). Despite the fact that metastatic disease is most commonly seen in older patients ( $>40$ years) with bone lesions, primary bone sarcomas and most frequently chondrosarcoma must also be taken into consideration (1). Therefore, while a diagnosis 
Table I. Detailed study characteristics of included publications.

\begin{tabular}{|c|c|c|c|c|c|c|}
\hline ID & Study & Year & Region & Country & Study type & $\mathrm{LoE}$ \\
\hline 1 & Soeharno et al. (21) & 2018 & Australia & Australia & Review article & 5 \\
\hline 2 & Johnson et al. (41) & 2019 & North America & USA & Review article & 5 \\
\hline 3 & Guerrieri et al. (42) & 2020 & Europe & Italy & Review article & 5 \\
\hline 4 & Ahmed et al. (40) & 2019 & North America & USA & Review article & 5 \\
\hline 5 & Manabe et al. (35) & 2005 & Asia & Japan & Review article & 5 \\
\hline 6 & Shibata et al. (26) & 2016 & Asia & Japan & Guideline & n.a. \\
\hline 7 & Errani et al. (48) & 2017 & Europe & Italy & Review article & 5 \\
\hline 8 & Cheung et al. (22) & 2014 & North America & USA & Review article & 5 \\
\hline 9 & Agarwal et al. (32) & 2015 & Asia & India & Review article & 5 \\
\hline 10 & Liska et al. (37) & 2018 & Europe & Germany & Review article & 5 \\
\hline 11 & Bryson et al. (23) & 2015 & Europe & UK & Review article & 5 \\
\hline 12 & Capanna et al. (38) & 2014 & Europe & Italy & Recommendation & n.a. \\
\hline 13 & Malviya et al. (36) & 2012 & Europe & UK & Review article & 5 \\
\hline 14 & Molloy et al. (28) & 2013 & Europe & Ireland & Review article & 5 \\
\hline 15 & Hage et al. (19) & 2000 & North America & USA & Review article & 5 \\
\hline 16 & Weber et al. (25) & 2010 & North America & USA & Review article & 5 \\
\hline 17 & Swanson et al. (31) & 2000 & North America & USA & Review article & 5 \\
\hline 18 & Bhamra et al. (27) & 2012 & North America & USA & Review article & 5 \\
\hline 19 & Schmidt et al. (29) & 1995 & North America & USA & Review article & 5 \\
\hline 20 & Jehn et al. (20) & 2016 & Europe & Germany & Review article & 5 \\
\hline 21 & Szendrói et al. (34) & 2017 & Europe & Hungary & Review article & 5 \\
\hline 22 & Bickels et al. (30) & 2009 & Asia & Israel & Review article & 5 \\
\hline 23 & Ratasvuori et al. (39) & 2013 & Europe & Finland & Review article & 5 \\
\hline 24 & Ruggieri et al. (24) & 2010 & Europe & Italy & Review article & 5 \\
\hline 25 & Gupta et al. (17) & 2019 & Asia & India & Review article & 5 \\
\hline 26 & Isaac et al. (33) & 2020 & Europe & UK & Review article & 5 \\
\hline 27 & Willeumier et al. (18) & 2016 & Europe & Netherlands & Review article & 5 \\
\hline 28 & Kohno et al. (43) & 2008 & Asia & Japan & Review article & 5 \\
\hline 29 & Tillman et al. (44) & 1999 & Europe & UK & Recommendation & n.a. \\
\hline 30 & Haentjens et al. (45) & 1993 & Europe & Belgium & Review article & 5 \\
\hline 31 & Damron et al. (46) & 2000 & North America & USA & Review article & 5 \\
\hline 32 & Beauchamp et al. (47) & 2000 & North America & USA & Review article & 5 \\
\hline
\end{tabular}

LoE: Level of evidence; n.a.: not applicable.

and workup should be established for an unknown primary cause, each patient requires an individual approach $(1,13)$.

Due to its clinical importance and potential to cause complications, the treatment of bone metastases requires a multidisciplinary approach involving orthopaedic surgeons, oncologists, radiologists, and radiotherapists (15).

This study aimed to identify possible pitfalls and complications in the diagnosis and surgical treatment of bone metastases.

\section{Materials and Methods}

A sweeping literature search was undertaken and all studies published between January 1, 1985, and May 7, 2021 were examined. PubMed was the main database for the literature search. Additional potentially matching studies were pinpointed by crosssearching the referenced articles in terms of backward and forward citation. The review was conducted in keeping with the Preferred Reporting Items for Systematic Reviews and Meta-Analyses (PRISMA) guidelines (16). Therefore, the titles and abstracts in Pubmed were surveyed with the following search string: orthopaedic
OR orthopedic AND bone metastasis OR skeletal metastasis AND treatment OR diagnostic OR management. Two authors separately checked the published studies by title and thereafter by the abstract. Of these publications, all reviews, recommendations or guidelines reporting diagnostic and treatment principles for bone metastasis of the extremities were included. Furthermore, studies in English and German were included. Finally, only articles with full text were considered. Table I gives the characteristics of all cases. The flowchart for the literature analysis is given in Figure 1.

\section{Results}

Altogether, 99 studies were singled out. Based on the inclusion and exclusion criteria, 32 were determined to qualify for analysis and were analyzed according to a) diagnostic assumptions, b) estimated life expectancy, c) disease-specific treatment and d) operative considerations.

Diagnostic assumptions. Successful management of bone metastases requires a correct and detailed diagnostic workup $(17,18)$. Therefore, it is necessary to highlight different 


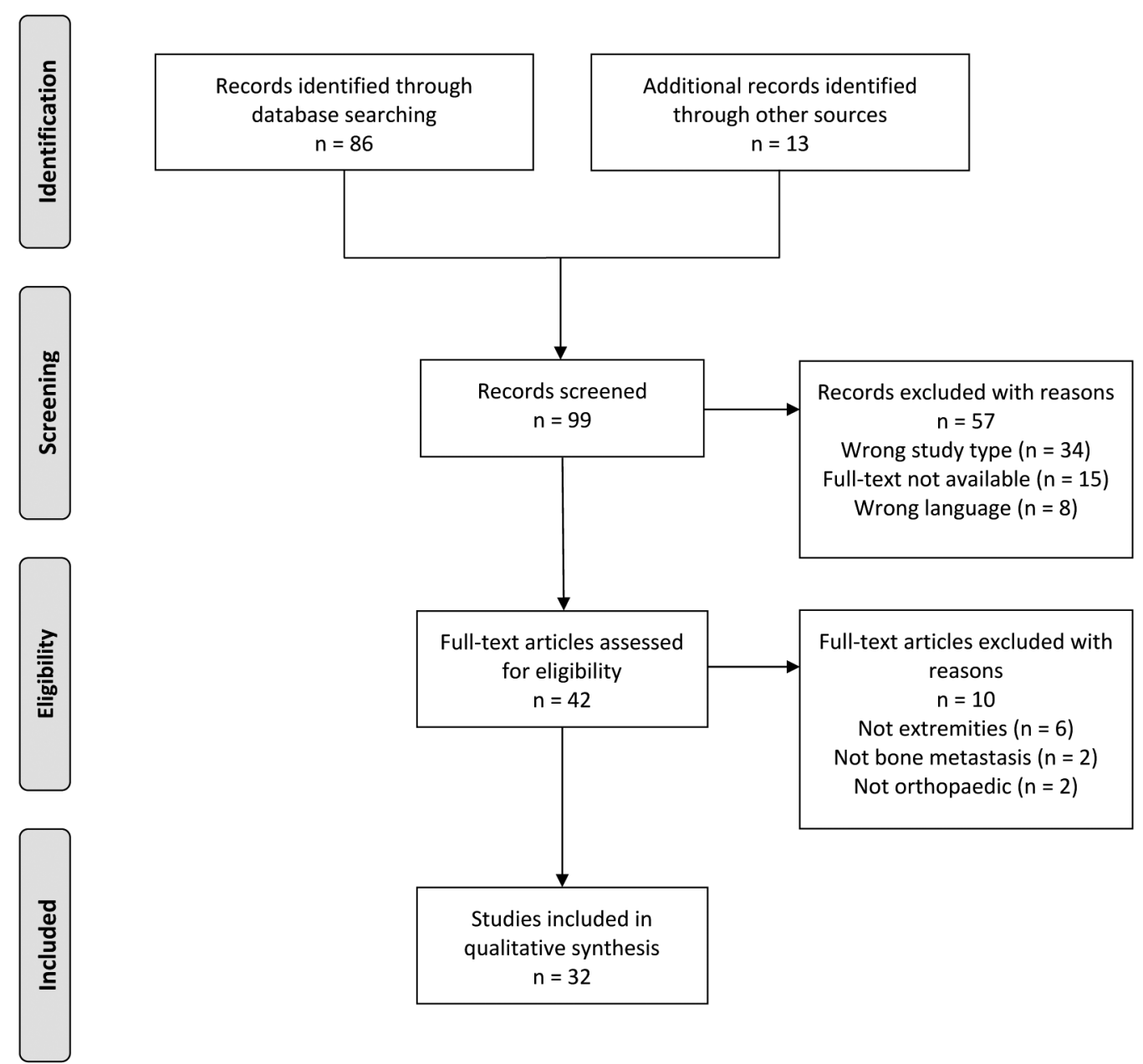

Figure 1. PRISMA flow chart showing study selection process.

scenarios in which the orthopaedic surgeon may be confronted upon bone metastasis (19).

Bone metastases in patients known to have a primary tumor can be asymptomatic and are found during staging or may present with pain or even pathological fractures (19, 20). It is a potential pitfall to assume that a lesion would be a metastasis. Because of this, confirmation of the diagnosis by biopsy is a must for any solitary lesion in a patient known to have a cancer disease $(18,21-24)$. The biopsy can be taken with a core needle or openly $(25,26)$. This should always be performed in accordance with the principles of musculoskeletal tumor biopsy as well as at an institution that is able to provide definitive disease treatment, as inappropriate biopsy performance can have a significant impact on the following procedure $(22,24)$. The biopsy pathway should be chosen to allow subsequent wide resection in tumor-free tissue and not adversely affect further limb surgery $(22,24)$. Therefore, in the case of a CT-guided needle biopsy, good communication between the performing radiologist and the orthopedic surgeon is paramount to avoid any discrepancy between the biopsy route and the planned surgical approach (24). In open biopsy, every effort should be made to prevent dissemination of possible cancer cells. For this reason, it is important to choose a direct approach by applying a longitudinal incision parallel to the underlying compartment, using a muscle-splitting technique, and ensuring good hemostasis before wound closure $(22,24)$. Additional histological confirmation can be omitted only when multiple lesions and carcinoma with a high risk of metastasis are present (18).

In addition to the scenario mentioned above, patients can also present with pain caused by a destructive bone lesion without known primary $(19,20,27)$. In this case, a bone lesion of unknown etiology is considered a primary bone tumor until proven differently $(18,21)$. In the case of a fracture, it is always necessary to determine whether it was 
caused by a related trauma or not (27). Pathological fractures are causally related to low-energy injuries and predominantly show a lytic lesion in the radiograph, which weakens the cortical bone (27). Failure to recognize the underlying problem combined with rushed surgical treatment of the fracture can have fatal consequences during further treatment. Therefore, highest priority is given to diagnostic workup rather than to rapid surgical treatment of the fracture (23). Although sensitivity for detecting small metastases is limited, $\mathrm{x}$-rays of the symptomatic bone and surrounding joints should always be performed $(21,22,28,29)$. It is essential to avoid missing proximal or distal metastases, as this can cause pathological fractures in precisely those areas when full weight bearing is applied after surgical fixation (30).

Radiologically, the characteristics of such lesions can be described as osteoblastic, osteolytic or mixed lytic-sclerotic and may hint at the possible primary $(20,21,23,28,31,32)$. While metastases due to prostate carcinoma are mostly osteoblastic, the bony lesions of lung, thyroid or renal primaries usually appear to be osteolytic $(21,23,25,31)$. By contrast, breast cancer metastases often show a mixed picture with lytic and sclerotic elements $(21,23,31)$. Additional three dimensionality of the anatomical sites as well as higher resolution are given by $\mathrm{CT}$ and magnetic resonance imaging (MRI) $(20-22,25,27,33)$. CT allows accurate visualization of cortical integrity and consequently assists in the evaluation of cortical bone destruction $(20,25,28,33,34)$. As previously mentioned, CT can also be useful in localizing the lesion in the setting of a percutaneous biopsy $(20,21)$.

With $91 \%$ sensitivity and $95 \%$ specificity, MRI is well suited to detect small bony metastases $(21,26,28)$. In addition, it provides valuable information about the extent of intramedullary as well as extraosseous soft tissue involvement, which helps in planning surgical and radiation therapy $(20,21,32,33)$.

Total-body scinti-scanning with technetium- $99 \mathrm{~m}$ is another diagnostic tool. It is a relatively inexpensive procedure that examines the entire body and is therefore suitable for determining the bone dissemination status in the initial staging of cancer disease and follow-up of disease-free patients (20$25,27,28,30,32)$. The principle is based on tracer uptake in areas of increased bone turnover rates, corresponding to elevated osteoblastic activity $(20,21)$. However, a number of other etiologies, such as inflammation, infection or trauma, may also result in tracer uptake (20). On the other hand, it should always be remembered that osteolytic metastases can give false-negative bone scans $(20,21)$.

Thanks to its increasing availability as well as improved sensitivity and specificity compared to scintigraphy, positron emission tomography-CT (PET-CT) is increasingly used (18). In addition, visceral disease locations are also revealed by PET-CT (18). When PET-CT is not available, the thorax, pelvis and abdomen should be examined by $\mathrm{CT}$ as part of staging to determine visceral dissemination $(18,27)$.
Life expectancy. Surgical treatment procedures in the setting of bone metastases aim to alleviate pain by bringing a local tumor under control and by maintaining or improving the patient's quality of life while reducing the risk of complications $(21,31$, $35,36)$. The choice of surgical procedure should strongly reflect the patient's estimated life expectancy $(20,21,24,37)$. Since life expectancy is multifactorially influenced, its estimation is a challenge $(21,22)$.

Many scores are available to calculate the patient's life expectancy. Thus, the Bayesian Belief Network (BBN) model serves as a tool in the decision-making process underlying surgical treatment by using clinical criteria to estimate the expected postoperative life span of patients with bone metastases $(17,21,38)$. The probability of survival at three and 12 months is calculated $(17,21,38)$. The significant factors influencing survival prediction for three months were the orthopaedic preoperative estimate of survival, Eastern Cooperative Oncology Group (ECOG) Performance Status, the concentration of hemoglobin, the absolute number of lymphocytes, and whether or not the patient has a pathological fracture (38). In contrast, the significant influencing factors in the 12-month model were orthopedic surgeon's estimate, hemoglobin concentration, how many bone metastases were identified and the type of primary tumor (38).

zThe final surgical procedure should always be selected for the individual patient (21). Underestimating life expectancy may result in failure to fix pathological fractures and hence may additionally be associated with significant limitations on quality of life. Therefore, no matter what fixation device is used it should be durable enough to ensure that it will survive the patient so as to avoid unnecessary reoperations necessitated by hardware failure $(28,31,39)$. Patients who are expected to survive longer should receive more aggressive treatment including wide resection and large-scale prosthetic reconstruction $(24,38)$. However, life expectancy should not be shorter than the combined duration of recovery and rehabilitation (18).

Bone metastases as a result of lung cancer or melanoma usually occur in multiple forms and show the worst outcome concerning survival, with an average survival of less than one year (34). While the one-year survival rate shown in studies for breast or renal cell carcinoma with operated bone metastases is still between $45 \%$ and $59 \%$, this figure drops sharply to $8 \%$ and to $20 \%$ within the first five years (34). For patients with systemic disease affecting the bone, such as multiple myeloma or non-Hodgkin's B-cell lymphoma, survival rates at 5 years have been reported to be $34 \%$ and $64 \%$, respectively (25).

Disease-specific treatment. Metastatic bone disease in patients with pathological fractures should be managed by a multidisciplinary team including oncologists, radiotherapists, surgeons, and physical therapists $(20,23,38,40)$. In addition 
to tumor type, treatment strategy for bony metastasis depends on the clinical features and includes further treatment options in addition to surgery (22).

Radiation therapy is a key adjunct in the management of metastatic disease patients and can also be used as monotherapy $(21,23)$. External beam radiation is commonly used to palliate pain from bone metastases, with one-third to $60 \%$ of patients experiencing complete pain relief $(17,21,23)$. In this context, reviews recommend 8 Gy given in one dose $(21,28)$.

Postoperatively or in patients with pathological fractures, radiation may also be helpful to prevent recurrence or progressive bone destruction $(22,24)$. However, incomplete irradiation of the surgical field should be avoided in order to rule out the development of periprosthetic metastases (22, 23). Despite the positive effects mentioned in the therapy of bone metastases, dose-dependent systemic and local sideeffects must always be considered. It should be noted that some metastatic lesions of carcinomas, such as renal cell carcinoma, are relatively resistant to radiation $(25,31)$.

Highly vascularised bone metastases occur especially in renal and thyroid carcinoma $(21,25,36)$. To minimize intraoperative blood loss in these cases, angiographically selective arterial embolization is recommended preoperatively $(21,25,30,38)$. Special care should be taken to embolize each feeding vessel of the bone lesion, as incomplete devascularizations have been documented to result in significantly higher intraoperative blood loss and transfusion requirements (21). In addition, embolization should be performed no more than 24 to 48 hours before surgery to minimize the risk of revascularization (41).

Because the receptor-activated nuclear factor kappa-B ligand (RANKL) attracts tumor cells to the bone to produce more RANKL, this increases osteoclast activity, leading to accelerated bone destruction (17). Bisphosphonates are available as an antiresorptive drug therapy option that inhibits osteoclast function and induces their apoptosis $(20,30,42)$. As bisphosphonates have been demonstrated to induce recalcification of lytic metastases, thereby reducing pain and the development of further lesions, they are standard treatment in breast cancer and multiple myeloma (21). Zoledronic acid and pamidronate have both been shown to induce a $30 \%$ reduction in skeletal morbidity, diminish the incidence of skeletal-related events (SRE) and significantly prolong time to first SRE in such patients $(17,20)$. However, rapid or high-dose intravenous application of bisphosphonates has been linked to osteonecrosis of the jaw and renal dysfunction (30). Furthermore, denosumab, a monoclonal antibody that binds to RANKL, can be used to inhibit osteoclast-mediated bone resorption (17). Denosumab has previously been seen to significantly inhibit the development of SRE in connection with bone metastases (21). Overall, initial therapy with bone-targeted agents is recommended immediately when bone metastases are detected with the aim of delaying time to first SRE (20).
Operative considerations. Although no strict surgical guideline prevails for skeletal metastases, consideration should be given to medical, clinical, radiological, and surgical factors together with the natural biology of the primary tumor as well as in the decision-making process (28). Surgery for metastatic disease calls for well-founded data on patient survival, and the main goals should be alleviation of pain, functional rehabilitation, and enhancement of quality of life rather than simple extension of lifetime (43). Careful diagnostic workup, preoperative examination, planning, and multidisciplinary cooperation by specialists in pathology, radiology, oncology, orthopaedics and trauma medicine are mandatory in the management of bone metastases $(23,25,44)$.

Pathological fractures are a clear indication for surgery with internal fixation, even when disease is advanced. In selected patients with advanced disease imminent fracture of a long bone can call for prophylactic fixation and subsequent postoperative radiation therapy $(20,45)$. In general, some simple rules on how to treat metastatic disease are recommended in the published literature (46):

1) The patient's prognosis should surpass the expected recovery time following surgery.

2) All regions of weakened bone, as well as any that may subsequently become weak, should be addressed in the intervention.

3) The applied fixation should permit prompt, full weight bearing and the orthopedic implant must outlast the patient's life expectancy.

4) Post-operative radiotherapy should be considered for all patients.

When it comes to metastases of the extremities, surgical treatment involves the possibility for manifold pitfalls. Assuming a lesion to be metastatic although it is a primary tumor might be one problem (47). Inadequate internal fixation might be another, as patients whose life expectancy is viewed in months should not have to live out their life with the consequences of poor internal fixation (47). The consequences of underestimating metastatic disease and its biological behavior may be catastrophic as metastatic lesions can be exceedingly vascular, which can be fatal if not recognized (47). Hasty surgical procedures can be a further source of error. A patient who presents with a pathological fracture requires prompt investigation, not prompt fracture management. Diagnosis must be established before surgery (47). All these pitfalls are avoidable by ensuring careful diagnostic workup, preoperative investigation, planning as well as multidisciplinary input from specialists.

\section{Discussion}

Management of metastatic bone lesions can be challenging and the possibilities for pitfalls and errors are numerous. Beauchamp 
et al. identified main causes of mistakes made in the treatment of bone and soft tissue neoplasms, stating that in almost one out of five patients with a bone or soft tissue neoplasm that patient's prognosis or outcome will be negatively influenced by a biopsy that is poorly planned, a diagnosis that is missed, or a surgical procedure that is otherwise ill-suited (47). One major source of error can be assuming a lesion to be metastatic when it is primary, possibly resulting in widespread contamination as a result of the surgical treatment. Therefore, a bone lesion whose etiology is unknown should be deemed a primary bone tumor until proven differently $(18,21)$.

Metastatic bone disease patients still commonly receive treatment at community hospitals $(48,49)$. However, such patients need to be referred to tertiary tumor centers, and orthopaedic oncology surgeons need to be familiar with how to manage patients with metastatic disease $(22,24,48,50)$. It is essential that orthopaedic oncology surgeons be called in early enough and not after a pathological fracture has already occurred (50). Early treatment, pain management, and functional amelioration are of utmost importance for cancer patients, particularly those with only a short time to live (48, 50). Therefore, not knowing when to refer a patient could be another source of error (51). The correct diagnosis has to be established first and any requisite investigations have to be conducted before the fracture is surgically repaired (51-54). The diagnosis must be established with certainty before the patient undergoes surgery. For patients presenting with primary bone lesions, limb salvage is the main goal (47).

The patient's anamnesis should be taken carefully, the fracture pattern closely examined, and the possibility of a malignancy should always be considered (47). X-rays of the symptomatic bone and surrounding joints should always be performed in first line $(21,28)$. CT allows accurate visualization of cortical integrity and thus assists in the evaluation of cortical bone destruction and can be useful in localizing the lesion in the setting of a percutaneous biopsy $(20,21,25,28,34)$. MRI is well suited to detect small bony metastases and provides valuable information about the extent of intramedullary as well as extraosseous soft tissue involvement $(20,21,28)$. PET-CT is a well-established diagnostic tool and can additionally provide information on visceral disease locations (18).

When it comes to surgical fixation, the goal has to be a fixation that is durable, rigid, and stable and that allows prompt, full weight bearing. Moreover, the life expectancy of the orthopedic implant must exceed that of the patient $(46,47)$. Instead of choosing a surgical technique that calls for protected weight-bearing endoprosthetic replacement, allowing immediate weight bearing should be preferred (55). In addition to the patient's preoperative neurological and performance status, the decisive factors are how aggressive the primary tumor is and how long the patient can be expected to live (20, 56). However, if overall survival is estimated to be prolonged, more aggressive interventions are justified. The use of internal fixation devices and prostheses have made a great contribution to the surgical management of pathological fractures $(28,57)$. Every patient deserves an evaluation that optimizes his chances to achieve the desired expectations and outcomes of surgical treatment while reducing morbidity to a minimum $(1,47)$.

In conclusion, treating a patient without having a secure diagnosis or without considering the possibility of malignancy is a fundamental source of error that will lead to a pitfall and may affect the life expectancy of the patient. Therefore, it is absolutely mandatory that each patient undergo an evaluation that optimizes his chances to achieve the wanted life expectancy and surgical outcome while reducing morbidity to a minimum. Treating patients with metastatic disease requires careful examination, a systematic and planned approach and should be managed and coordinated in a multidisciplinary team and a specialized tumor center.

\section{Conflicts of Interest}

The Authors declare that there are no conflicts of interest in relation to this study.

\section{Authors' Contributions}

D. Dammerer: study protocol, study design. P. Blum: literature research, data analysis, editing and writing of the article. D. Krappinger: co-editing and proofreading of the article. A. Keiler: literature research, editing, writing, and proofreading of the article. All Authors made pertinent contributions to the article, proofread, and approved the final article before submission.

\section{Acknowledgements}

Professional language editing of the manuscript by Mary Heaney Margreiter is acknowledged.

\section{References}

1 Denaro V, Di Martino A and Piccioli A: Management of bone metastases: A multidisciplinary guide. Berlin, Springer, 2019.

2 WHO Expert Committee on Cancer Pain Relief and Active Supportive Care \& World Health Organization: Cancer pain relief and palliative care: report of a WHO expert committee [meeting held in Geneva from 3 to 10 July 1989]. World Health Organization, Geneva, 1990. Available at: http://apps.who. int/iris/bitstream/handle/10665/39524/WHO_TRS_804.pdf?sequ ence $=1$ [Last accessed on September 8, 2021]

3 Macedo F, Ladeira K, Pinho F, Saraiva N, Bonito N, Pinto L and Goncalves F: Bone metastases: an overview. Oncol Rev 11(1): 321, 2017. PMID: 28584570. DOI: 10.4081/oncol.2017.321

4 Siegel GW, Biermann JS, Calinescu AA, Spratt DE and Szerlip NJ: Surgical approach to bone metastases. Curr Osteoporos Rep 16(4): 512-518, 2018. PMID: 29915966. DOI: 10.1007/s11914018-0463-7

5 Chaffer CL and Weinberg RA: A perspective on cancer cell metastasis. Science 331(6024): 1559-1564, 2011. PMID: 21436443. DOI: $10.1126 /$ science. 1203543 
6 Luzzi KJ, MacDonald IC, Schmidt EE, Kerkvliet N, Morris VL, Chambers AF and Groom AC: Multistep nature of metastatic inefficiency: dormancy of solitary cells after successful extravasation and limited survival of early micrometastases. Am J Pathol 153(3): 865-873, 1998. PMID: 9736035. DOI: 10.1016/S0002-9440(10)65628-3

7 Clézardin P: Pathophysiology of bone metastases from solid malignancies. Joint Bone Spine 84(6): 677-684, 2017. PMID: 28499894. DOI: 10.1016/j.jbspin.2017.05.006

8 Selvaggi G and Scagliotti GV: Management of bone metastases in cancer: a review. Crit Rev Oncol Hematol 56(3): 365-378, 2005. PMID: 15978828. DOI: 10.1016/j.critrevonc.2005.03.011

9 Coleman RE: Metastatic bone disease: clinical features, pathophysiology and treatment strategies. Cancer Treat Rev 27(3): 165-176, 2001. PMID: 11417967. DOI: 10.1053/ctrv.2000.0210

10 Cecchini M, Wetterwald A, Pluijm G and Thalmann G: Molecular and biological mechanisms of bone metastasis. EAU Update Series 3(4): 214-226, 2021. DOI: 10.1016/j.euus 2005.09.006

11 Lipton A, Theriault RL, Hortobagyi GN, Simeone J, Knight RD, Mellars K, Reitsma DJ, Heffernan $M$ and Seaman JJ: Pamidronate prevents skeletal complications and is effective palliative treatment in women with breast carcinoma and osteolytic bone metastases: long term follow-up of two randomized, placebo-controlled trials. Cancer 88(5): 1082-1090, 2000. PMID: 10699899. DOI: 10.1002/(sici)1097-0142(20000 301) $88: 5<1082::$ aid-cncr20>3.0.co; $2-\mathrm{z}$

12 Briasoulis E, Karavasilis V, Kostadima L, Ignatiadis M, Fountzilas $\mathrm{G}$ and Pavlidis N: Metastatic breast carcinoma confined to bone: portrait of a clinical entity. Cancer 101(7): 1524-1528, 2004. PMID: 15316943. DOI: 10.1002/cncr.20545

13 Rougraff BT: Evaluation of the patient with carcinoma of unknown origin metastatic to bone. Clin Orthop Relat Res (415 Suppl): S105-S109, 2003. PMID: 14600599. DOI: 10.1097/ 01.blo.0000093049.96273.e3

14 Keiler A, Dammerer D, Liebensteiner M, Schmitz K, Kaiser P and Wurm A: Pathological fracture of the tibia as a first sign of hyperparathyroidism - a case report and systematic review of the current literature. Anticancer Res 41(6): 3083-3089, 2021. PMID: 34083301. DOI: 10.21873/anticanres.15092

15 Migliorini F, Maffulli N, Trivellas A, Eschweiler J, Tingart M and Driessen A: Bone metastases: a comprehensive review of the literature. Mol Biol Rep 47(8): 6337-6345, 2020. PMID: 32749632. DOI: $10.1007 / \mathrm{s} 11033-020-05684-0$

16 Moher D, Liberati A, Tetzlaff J, Altman DG and PRISMA Group: Preferred reporting items for systematic reviews and metaanalyses: the PRISMA statement. PLoS Med 6(7): e1000097, 2009. PMID: 19621072. DOI: 10.1371/journal.pmed.1000097

17 Gupta S, Gulia A, Kurisunkal V, Parikh M and Gupta S: Principles of management of extremity skeletal metastasis. Indian J Palliat Care 25(4): 580-586, 2019. PMID: 31673216. DOI: 10.4103/IJPC.IJPC_90_19

18 Willeumier JJ, van der Linden YM, van de Sande MAJ and Dijkstra PDS: Treatment of pathological fractures of the long bones. EFORT Open Rev 1(5): 136-145, 2017. PMID: 28461940. DOI: $10.1302 / 2058-5241.1 .000008$

19 Hage WD, Aboulafia AJ and Aboulafia DM: Incidence, location, and diagnostic evaluation of metastatic bone disease. Orthop Clin North Am 31(4): 515-28, vii, 2000. PMID: 11043092. DOI: 10.1016/s0030-5898(05)70171-1
20 Jehn CF, Diel IJ, Overkamp F, Kurth A, Schaefer R, Miller K and Lüftner D: Management of metastatic bone disease algorithms for diagnostics and treatment. Anticancer Res 36(6): 2631-2637, 2016. PMID: 27272771.

21 Soeharno H, Povegliano L and Choong PF: Multimodal treatment of bone metastasis-a surgical perspective. Front Endocrinol (Lausanne) 9: 518, 2018. PMID: 30245668. DOI: 10.3389/fendo.2018.00518

22 Cheung FH: The practicing orthopedic surgeon's guide to managing long bone metastases. Orthop Clin North Am 45(1): 109-119, 2014. PMID: 24267212. DOI: 10.1016/j.ocl.2013.09.003

23 Bryson DJ, Wicks L and Ashford RU: The investigation and management of suspected malignant pathological fractures: a review for the general orthopaedic surgeon. Injury 46(10): 18911899, 2015. PMID: 26254572. DOI: 10.1016/j.injury.2015.07.028

24 Ruggieri P, Mavrogenis AF, Casadei R, Errani C, Angelini A, Calabrò T, Pala E and Mercuri M: Protocol of surgical treatment of long bone pathological fractures. Injury 41(11): 1161-1167, 2010. PMID: 20947077. DOI: 10.1016/j.injury.2010.09.018

25 Weber KL: Evaluation of the adult patient (aged $>40$ years) with a destructive bone lesion. J Am Acad Orthop Surg 18(3): 169-179, 2010. PMID: 20190107. DOI: 10.5435/00124635-201003000-00006

26 Shibata H, Kato S, Sekine I, Abe K, Araki N, Iguchi H, Izumi T, Inaba Y, Osaka I, Kato S, Kawai A, Kinuya S, Kodaira M, Kobayashi E, Kobayashi T, Sato J, Shinohara N, Takahashi S, Takamatsu Y, Takayama K, Takayama K, Tateishi U, Nagakura H, Hosaka M, Morioka H, Moriya T, Yuasa T, Yurikusa T, Yomiya $\mathrm{K}$ and Yoshida M: Diagnosis and treatment of bone metastasis: comprehensive guideline of the Japanese Society of Medical Oncology, Japanese Orthopedic Association, Japanese Urological Association, and Japanese Society for Radiation Oncology. ESMO Open 1(2): e000037, 2016. PMID: 27843593. DOI: 10.1136/esmoopen-2016-000037

27 Bhamra JS, Malik AA, Aresti NA, Khan WS and Pollock R: The perioperative management of skeletal metastases. J Perioper Pract 22(1): 24-29, 2012. PMID: 22324118. DOI: 10.1177/ 175045891202200104

28 Molloy AP and O'Toole GC: Orthopaedic perspective on bone metastasis. World J Orthop 4(3): 114-119, 2013. PMID: 23878778. DOI: $10.5312 /$ wjo.v4.i3.114

29 Schmidt RG: Management of extremity metastatic bone cancer. Curr Probl Cancer 19(3): 166-182, 1995. PMID: 7545570. DOI: 10.1016/s0147-0272(06)80009-7

30 Bickels J, Dadia S and Lidar Z: Surgical management of metastatic bone disease. J Bone Joint Surg Am 91(6): 15031516, 2009. PMID: 19487532. DOI: 10.2106/JBJS.H.00175

31 Swanson KC, Pritchard DJ and Sim FH: Surgical treatment of metastatic disease of the femur. J Am Acad Orthop Surg 8(1): 56-65, 2000. PMID: 10666653. DOI: 10.5435/00124635-20000 1000-00006

32 Agarwal MG and Nayak P: Management of skeletal metastases: An orthopaedic surgeon's guide. Indian J Orthop 49(1): 83-100, 2015. PMID: 25593359. DOI: 10.4103/0019-5413.143915

33 Isaac A, Dalili D, Dalili D and Weber MA: State-of-the-art imaging for diagnosis of metastatic bone disease. Radiologe 60(Suppl 1): 1-16, 2020. PMID: 32211916. DOI: 10.1007/ s00117-020-00666-6

34 Szendrői M, Antal I, Szendrői A, Lazáry Á and Varga PP: Diagnostic algorithm, prognostic factors and surgical treatment of metastatic cancer diseases of the long bones and spine. 
EFORT Open Rev 2(9): 372-381, 2017. PMID: 29071122. DOI: 10.1302/2058-5241.2.170006

35 Manabe J, Kawaguchi N, Matsumoto S and Tanizawa T: Surgical treatment of bone metastasis: indications and outcomes. Int J Clin Oncol 10(2): 103-111, 2005. PMID: 15864695. DOI: 10.1007/s10147-005-0478-9

36 Malviya A and Gerrand C: Evidence for orthopaedic surgery in the treatment of metastatic bone disease of the extremities: a review article. Palliat Med 26(6): 788-796, 2012. PMID: 21930647. DOI: $10.1177 / 0269216311419882$

37 Liska F, Schmitz P, Harrasser N, Prodinger P, Rechl H and von Eisenhart-Rothe R: [Metastatic disease in long bones: Review of surgical treatment options]. Unfallchirurg 121(1): 37-46, 2018. PMID: 27904933. DOI: 10.1007/s00113-016-0282-1

38 Capanna R, Piccioli A, Di Martino A, Daolio PA, Ippolito V, Maccauro G, Piana R, Ruggieri P, Gasbarrini A, Spinelli MS, Campanacci DA and Italian Orthopaedic Society Bone Metastasis Study Group: Management of long bone metastases: recommendations from the Italian Orthopaedic Society bone metastasis study group. Expert Rev Anticancer Ther 14(10): 11271134, 2014. PMID: 25151850. DOI: 10.1586/14737140. 2014.947691

39 Ratasvuori M, Wedin R, Keller J, Nottrott M, Zaikova O, Bergh P, Kalen A, Nilsson J, Jonsson H and Laitinen M: Insight opinion to surgically treated metastatic bone disease: Scandinavian Sarcoma Group Skeletal Metastasis Registry report of 1195 operated skeletal metastasis. Surg Oncol 22(2): 132-138, 2013. PMID: 23562148. DOI: 10.1016/j.suronc.2013.02.008

40 Ahmed $\mathrm{O}$, Feinberg $\mathrm{N}$ and Lea WB: Interventional techniques for the ablation and augmentation of extraspinal lytic bone metastases. Semin Intervent Radiol 36(3): 221-228, 2019. PMID: 31435130. DOI: 10.1055/s-0039-1693117

41 Johnson CN, Gurich RW Jr, Pavey GJ and Thompson MJ: Contemporary management of appendicular skeletal metastasis by primary tumor type. J Am Acad Orthop Surg 27(10): 345355, 2019. PMID: 30394910. DOI: 10.5435/JAAOS-D-17-00749

42 Guerrieri AN, Montesi M, Sprio S, Laranga R, Mercatali L, Tampieri A, Donati DM and Lucarelli E: Innovative options for bone metastasis treatment: An extensive analysis on biomaterials-based strategies for orthopedic surgeons. Front Bioeng Biotechnol 8: 589964, 2020. PMID: 33123519. DOI: 10.3389/fbioe. 2020.589964

43 Kohno N: Treatment of breast cancer with bone metastasis: bisphosphonate treatment - current and future. Int J Clin Oncol 13(1): 18-23, 2008. PMID: 18307015. DOI: 10.1007/s10147007-0726-2

44 Tillman RM: The role of the orthopaedic surgeon in metastatic disease of the appendicular skeleton. Working Party on Metastatic Bone Disease in Breast Cancer in the UK. J Bone Joint Surg Br 81(1): 1-2, 1999. PMID: 10067992. DOI: 10.1302/0301-620x.81b1.9514

45 Haentjens P, Casteleyn PP and Opdecam P: Evaluation of impending fractures and indications for prophylactic fixation of metastases in long bones. Review of the literature. Acta Orthop Belg 59(Suppl 1): 6-11, 1993. PMID: 8116441.
46 Damron TA and Sim FH: Surgical treatment for metastatic disease of the pelvis and the proximal end of the femur. Instr Course Lect 49: 461-470, 2000. PMID: 10829199.

47 Beauchamp CP: Errors and pitfalls in the diagnosis and treatment of metastatic bone disease. Orthop Clin North Am 31(4): 675-685, 2000. PMID: 11043105. DOI: 10.1016/s00305898(05)70184-x

48 Errani C, Mavrogenis AF, Cevolani L, Spinelli S, Piccioli A, Maccauro G, Baldini N and Donati D: Treatment for long bone metastases based on a systematic literature review. Eur J Orthop Surg Traumatol 27(2): 205-211, 2017. PMID: 27650452. DOI: 10.1007/s00590-016-1857-9

49 Weber KL, Randall RL, Grossman S and Parvizi J: Management of lower-extremity bone metastasis. J Bone Joint Surg Am 88(Suppl 4): 11-19, 2006. PMID: 17142431. DOI: $10.2106 /$ JBJS.F.00635

50 Ratasvuori M, Wedin R, Hansen BH, Keller J, Trovik C, Zaikova O, Bergh P, Kalen A and Laitinen M: Prognostic role of en-bloc resection and late onset of bone metastasis in patients with boneseeking carcinomas of the kidney, breast, lung, and prostate: SSG study on 672 operated skeletal metastases. J Surg Oncol 110(4): 360-365, 2014. PMID: 24889389. DOI: 10.1002/jso.23654

51 deSantos LA, Murray JA and Ayala AG: The value of percutaneous needle biopsy in the management of primary bone tumors. Cancer 43(2): 735-744, 1979. PMID: 217529. DOI: 10.1002/10970142(197902)43:2<735::aid-cncr2820430250>3.0.co;2-h

52 El-Khoury GY, Terepka RH, Mickelson MR, Rainville KL and Zaleski MS: Fine-needle aspiration biopsy of bone. J Bone Joint Surg Am 65(4): 522-525, 1983. PMID: 6833329.

53 Yazawa Y, Frassica FJ, Chao EY, Pritchard DJ, Sim FH and Shives TC: Metastatic bone disease. A study of the surgical treatment of 166 pathologic humeral and femoral fractures. Clin Orthop Relat Res (251): 213-219, 1990. PMID: 2295178.

54 Wahner $\mathrm{H}$ and Brown M: Role of bone scanning. New York, Raven Press, 1988.

55 Clarke HD, Damron TA and Sim FH: Head and neck replacement endoprosthesis for pathologic proximal femoral lesions. Clin Orthop Relat Res (353): 210-217, 1998. PMID: 9728176. DOI: 10.1097/00003086-199808000-00024

56 Sioutos PJ, Arbit E, Meshulam CF and Galicich JH: Spinal metastases from solid tumors. Analysis of factors affecting survival. Cancer 76(8): 1453-1459, 1995. PMID: 8620423. DOI: 10.1002/1097-0142(19951015)76:8<1453::aid-cncr2 820760824>3.0.co;2-t

57 Marco RA, Sheth DS, Boland PJ, Wunder JS, Siegel JA and Healey JH: Functional and oncological outcome of acetabular reconstruction for the treatment of metastatic disease. J Bone Joint Surg Am 82(5): 642-651, 2000. PMID: 10819275 . DOI: 10.2106/00004623-200005000-00005

Received August 18, 2021

Revised September 7, 2021

Accepted September 8, 2021 